\title{
Ancient grandeur of the vertebrate neuropeptide Y system shown by the coelacanth Latimeria chalumnae
}

\section{Dan Larhammar * and Christina A. Bergqvist}

Unit of Pharmacology, Department of Neuroscience, Science for Life Laboratory - Uppsala University, Uppsala, Sweden

\section{Edited by:}

Jae Young Seong, Korea University, South Korea

\section{Reviewed by:}

Hervé Tostivint, Natural History

Museum, France

Stacia A. Sower, University of New

Hampshire, USA

${ }^{*}$ Correspondence:

Dan Larhammar, Unit of

Pharmacology, Department of

Neuroscience, Science for Life

Laboratory - Uppsala University, Box 593, SE-751 24 Uppsala, Sweden. e-mail:dan.larhammar@neuro.uu.se

The neuropeptide Y (NPY) family receptors and peptides have previously been characterized in several tetrapods, teleost fishes, and in a holocephalan cartilaginous fish. This has shown that the ancestral NPY system in the jawed vertebrates consisted of the peptides NPY and peptide YY (PYY) and seven G-protein-coupled receptors named Y1-Y8 (Y3 does not exist). The different vertebrate lineages have subsequently lost or gained a few receptor genes. For instance, the human genome has lost three of the seven receptors while the zebrafish has lost two and gained two receptor genes. Here we describe the NPY system of a representative of an early diverging lineage among the sarcopterygians, the West Indian Ocean coelacanth Latimeria chalumnae. The coelacanth was found to have retained all seven receptors from the ancestral jawed vertebrate. The receptors display the typical characteristics found in other vertebrates. Interestingly, the coelacanth was found to have the local duplicate of the PYY gene, called pancreatic polypeptide, previously only identified in tetrapods. Thus, this duplication took place very early in the sarcopterygian lineage, before the origin of tetrapods. These findings confirm the ancient complexity of the NPY system and show that mammals have lost more NPY receptors than any other vertebrate lineage. The coelacanth has all three peptides found in tetrapods and has retained the ancestral jawed vertebrate receptor repertoire with neither gains or losses.

Keywords: G-protein-coupled receptor, neuropeptide $Y$, peptide $Y Y$, pancreatic polypeptide, coelacanth, Latimeria chalumnae

\section{INTRODUCTION}

Neuropeptide Y (NPY) and its related peptides named peptide YY (PYY) and pancreatic polypeptide (PP) comprise a system of neuronal and endocrine peptides that act on several G-proteincoupled receptors in vertebrates. They are involved in the regulation of a broad range of functions including appetite/satiety, gut motility, cardiovascular activity, pituitary release of hormones, circadian rhythm, and many more (see Pedrazzini et al., 2003; Brumovsky et al., 2007; Mercer et al., 2011; Zhang et al., 2011 for reviews). NPY and PYY arose by duplication of a common ancestral peptide gene before the vertebrate radiation (Larhammar, 1996). In mammals NPY is almost exclusively neuronal whereas PYY is primarily expressed in endocrine cells in the gastrointestinal tract. In ray finned fishes, PYY too is expressed in the nervous system (Cerdá-Reverter et al., 2000; Söderberg et al., 2000). PP is a local duplicate of PYY (Hort et al., 1995) previously found only in tetrapods (Larhammar, 1996; Cerdá-Reverter and Larhammar, 2000; Conlon, 2002; Sundstrom et al., 2008) and is expressed in pancreatic islets.

Mammals generally possess four receptors for the NPY-family peptides, namely subtypes Y1, Y2, Y4, and Y5 (Larhammar and Salaneck, 2004). Subtype Y3 was postulated from pharmacological experiments but does not exist as a separate gene (Herzog et al., 1993; Jazin et al., 1993). A fifth receptor gene, Y6, is expressed in a few mammals such as mouse and rabbit but is a pseudogene in many others including primates (Matsumoto et al., 1996), pig (Wraith et al., 2000), and guinea-pig (Starbäck et al., 2000). With its three peptides and four receptors, the NPY system in humans and most other mammals displays a degree of complexity resembling many other vertebrate peptide-receptor systems for neuronal and endocrine peptides, for instance the melanocortin system (Dores and Baron, 2011; Liang et al., 2013), the opioid system (Sundstrom et al., 2010), the oxytocin-vasopressin system (Ocampo Daza et al., 2011; Yamaguchi et al., 2012), and the somatostatin-cortistatin system (Tostivint et al., 2008; Ocampo Daza et al., 2012). However, previous evolutionary studies of the NPY receptor family have shown that a larger number of receptors existed in the early stages of vertebrate evolution before the emergence of jawed vertebrates, Gnathostomata: by sequence-based phylogenetic analyses and comparison of gene locations on chromosomes, we were able to deduce an ancestral vertebrate set of no less than seven NPY-family receptors (Larhammar and Salaneck, 2004; Larsson et al., 2008), more than for any other known peptide-receptor family. Subsequently, this repertoire was confirmed by our identification of all seven receptor subtypes in a cartilaginous fish (Chondrichthyes), the holocephalan elephant shark, or ghost shark, Callorhinchus milii (Larsson et al., 2009). Thus, the following evolutionary scenario was corroborated: an ancestral pre-vertebrate chromosome carried the genes for a Y1-like, a Y2-like, and a Y5like receptor subtype. The two basal vertebrate tetraploidizations (Nakatani et al., 2007; Putnam et al., 2008) quadrupled this chromosome, thereby generating four similar chromosomal regions that probably had as many as $12(4 \times 3)$ family members, unless some were lost already after the first tetraploidization. In extant 
Table 1 | The table lists Ensemble gene ID or NCBI accession number for the coelacanth NPY-family receptor and peptide genes as well as the orthologs genes in human, chicken, zebrafish, and elephant shark.

\begin{tabular}{|c|c|c|c|c|}
\hline Species & Receptor & $\begin{array}{l}\text { Ensembl gene ID/NCBI } \\
\text { accession number }\end{array}$ & $\begin{array}{l}\text { Genome } \\
\text { assembly }\end{array}$ & Comment \\
\hline Coelacanth & Y1 & ENSLACG00000009650 & LatCha1 & Manually curated \\
\hline Chicken & $Y_{1}$ & NM_001031535 & & \\
\hline Zebrafish & $Y_{1}$ & EU046342 & & \\
\hline Elephant shark & $\mathrm{Y}_{1}$ & EU637847 & & \\
\hline Human & Y2 & NM_000910 & & \\
\hline Chicken & Y2 & NM_001031128 & & \\
\hline Zebrafish & Y2 & XP_001343301 & & \\
\hline Zebrafish & Y2-2 & XP_001332759 & & \\
\hline Elephant shark & Y2 & EU637848 & & \\
\hline Zebrafish & Y4 & AF037400 & & \\
\hline Elephant shark & Y4 & EU637849 & & \\
\hline Coelacanth & Y5 & ABI94072.1 & & \\
\hline Human & Y5 & NM_006174 & & \\
\hline Chicken & Y5 & NM_001031130 & & \\
\hline Elephant shark & Y5 & EU637850 & & \\
\hline Coelacanth & Y6 & ABI94073.1 & & \\
\hline Mouse & Y6 & ENSMUSG00000038071 & $\mathrm{GRCm} 38$ & \\
\hline Chicken & Y6 & ENSGALG00000021235 & WASHUC2 & Manually curated \\
\hline Elephant shark & Y6 & EU637851 & & \\
\hline Coelacanth & Y7 & ENSLACG00000013918 & LatCha1 & Manually curated \\
\hline Human & SSTR1 & ENSG00000139874 & GRCh37 & \\
\hline
\end{tabular}

For Y6, the mouse sequence is included instead of the human pseudogene. The human somatostatin receptor SSTR1 that was used as outgroup in the phylogenetic tree is also included.

The coelacanth entries are shown in bold.

vertebrate lineages a total of seven family members have been found to remain: four Y1-subfamily genes with one on each of the four chromosomes resulting from the tetraploidizations (Y1, Y4, Y6, and Y8), two Y2-like genes (Y2 linked to Y1, Y7 linked to Y6), and a single surviving $\mathrm{Y} 5$ gene (linked to $\mathrm{Y} 1$ and $\mathrm{Y} 2$ ) (Larsson et al., 2008, 2009).

Of the vertebrates investigated to date only the elephant shark has maintained all seven of these ancestral vertebrate receptor genes (Larsson et al., 2009). All of the other gnathostome lineages seem to have suffered losses, although some of the genome databases may be incomplete. Among amphibians, the western clawed frog Silurana (Xenopus) tropicalis seems to have lost Y6 which appears to be a pseudogene in the frog Pelophylax esculentus (previously called Rana esculenta; Sundstrom et al., 2012).
Amniotes have lost $\mathrm{Y} 8$, or possibly this gene was lost independently in birds and mammals (Larsson et al., 2009). The mammalian lineage subsequently lost also Y7. The Y6 gene is a pseudogene in several mammals as mentioned above. In the large and heterogeneous group of rayfinned fishes (Actinopterygii), the teleosts are the most carefully studied. In the true teleost species (Euteleostei) with sequenced genomes, the receptors $\mathrm{Y} 1, \mathrm{Y} 2, \mathrm{Y} 4, \mathrm{Y} 7$, and $\mathrm{Y} 8$, as well as a duplicate of Y8 called Y8b, have been identified, albeit only the zebrafish genome contains all of these (Larsson et al., 2008; Salaneck et al., 2008). Thus, the Y8 duplicate seems to be the only surviving copy resulting from the teleost-specific third tetraploidization, 3R (Jaillon et al., 2004). Also, this suggests that $\mathrm{Y} 5$ and $\mathrm{Y} 6$ are missing in Euteleostei. A local duplicate of Y2, named Y2-2, has been found in zebrafish and medaka (Fallmar et al., 
2011). In addition, Y5 and Y6 have been identified in more basally diverging rayfinned fish species, namely a sturgeon and a bichir, as well as an early diverging teleost, the silver arowana, Osteoglossum bicirrhosum (Salaneck et al., 2008). Also, we have previously cloned the genes for Y5 and Y6 from the coelacanth Latimeria chalumnae (Lch; Larsson et al., 2007). The receptor gene duplication scenario is further supported by findings in lampreys of members of the Y1, Y2, and Y5 lineages (Salaneck et al., 2001; Larsson et al., 2009; Xu et al., 2012). In summary, of all gnathostome species that have been previously investigated only the elephant shark seems to have retained the complete ancestral repertoire of seven NPY receptor genes.

The West Indian Ocean coelacanth, Lch, is an important species for studies of vertebrate evolution as it is one of only two extant and closely related coelacanth species representing a very early Actinistia branch among the lobe finned fishes, Sarcopterygii. The relationship of coelacanths to lungfishes (Dipnoi) and tetrapods has been difficult to resolve. Recent data suggest that the coelacanths are slightly more closely related to the lungfishes than either of these groups is to tetrapods (Shan and Gras, 2011). The Actinopterygii-Sarcopterygii divergence took place approximately 424 million years ago (Mya) according to a recent estimate based on molecular data (Chen et al., 2012). The coelacanth and tetrapod lineages may have parted only a few tens of millions of years later, well before the split of the amphibian and amniote lineages approximately 350 Mya. Thus, it is of great interest to see which genetic and phenotypic Sarcopterygian characters had already arisen before the coelacanth-tetrapod divergence. In September
2011, a new genome assembly became available for the coelacanth. We present here a genomic analysis of the NPY system in Lch, identifying not only the receptor repertoire but also the genes for the three peptide ligands that bind to these receptors.

\section{MATERIALS AND METHODS}

The PreEnsembl sequence database (ENSEMBL LatCha1 released September 2011, database version 69.1) for the West Indian Ocean coelacanth Lch was searched with Blast/Blat using as query sequences the human NPY-family receptors Y1, Y2, and Y4, and the zebrafish receptors $Y 7$ and $8 \mathrm{~b}$. Five new receptors were identified, all but Y4 are annotated in Ensembl68. Amino acid sequences for NPY receptors from the following species were used for alignments: human (Homo sapiens), chicken (Gallus gallus), zebrafish (Danio rerio), elephant shark (C. milii), mouse (Mus musculus), and coelacanth (L. chalumnae). A list of genes with corresponding accession numbers is provided in Table $\mathbf{1}$ with the coelacanth NPY receptor sequences in bold.

Amino acid alignments were made in Jalview 2.8 version 14.0 (Waterhouse et al., 2009) using the MUSCLE and Clustal W web tool with standard settings. Phylogenetic NeighborJoining (NJ; Saitou and Nei, 1987) trees were made by using Clustal X version 2.0.12 (Larkin et al., 2007), standard settings and 1000 bootstrap replicates were applied. The tree shown in Figure 2 was rooted with the human somatostatin receptor sequence SSTR1. Phylogenetic trees were also made with the Maximum Likelihood (ML) method (Guindon et al., 2010).

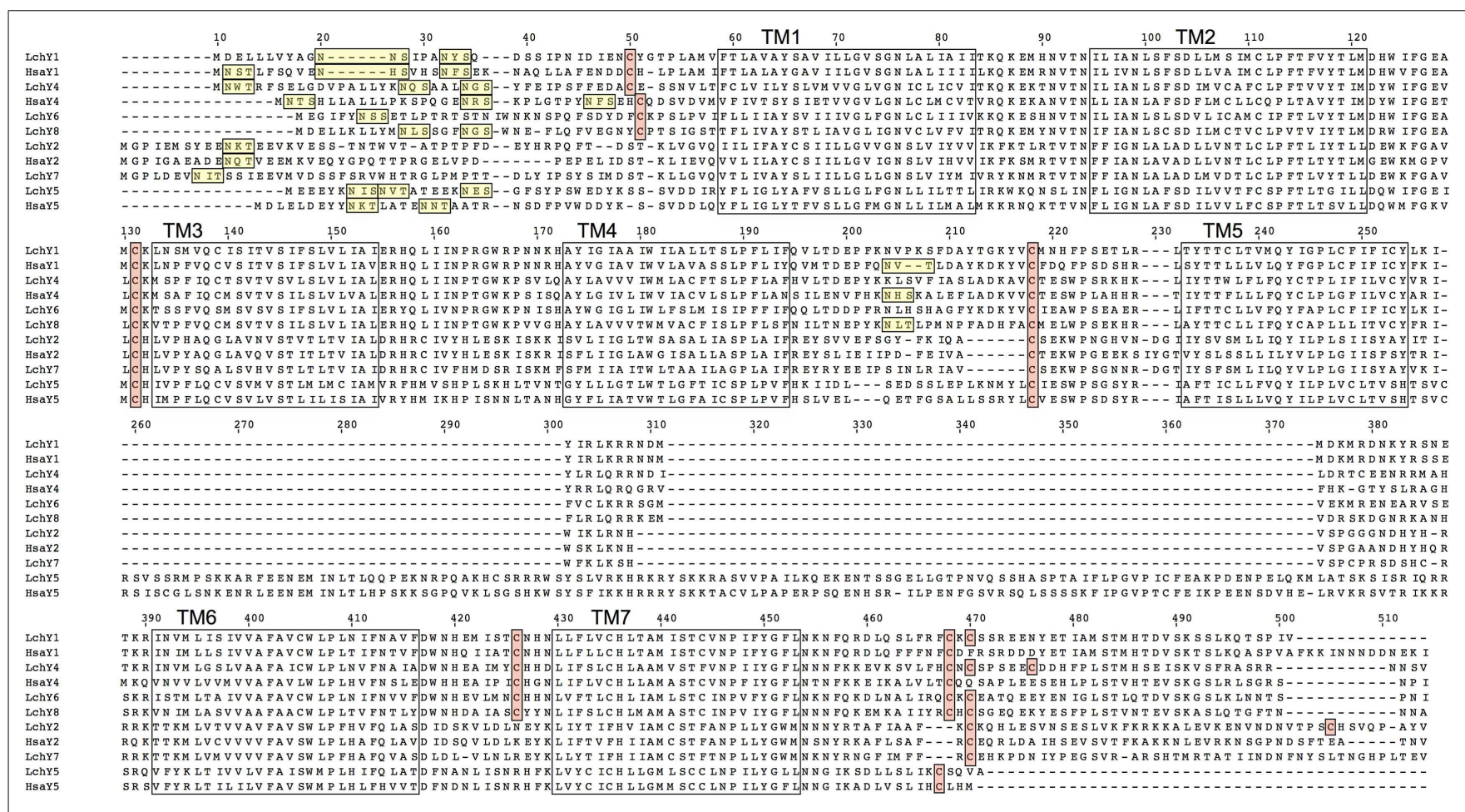

FIGURE 1 | Alignment of all coelacanth and human NPY-family receptor sequences except the human hY6 pseudogene. The seven transmembrane regions are marked with boxes. Consensus sequences for asparagine-linked glycosylation in the aminoterminal region are underlined. Cysteines assumed to be involved in disulfide bonds are within boxes as are the cysteines in the carboxyterminal region that may serve as attachment sites for palmitate. 


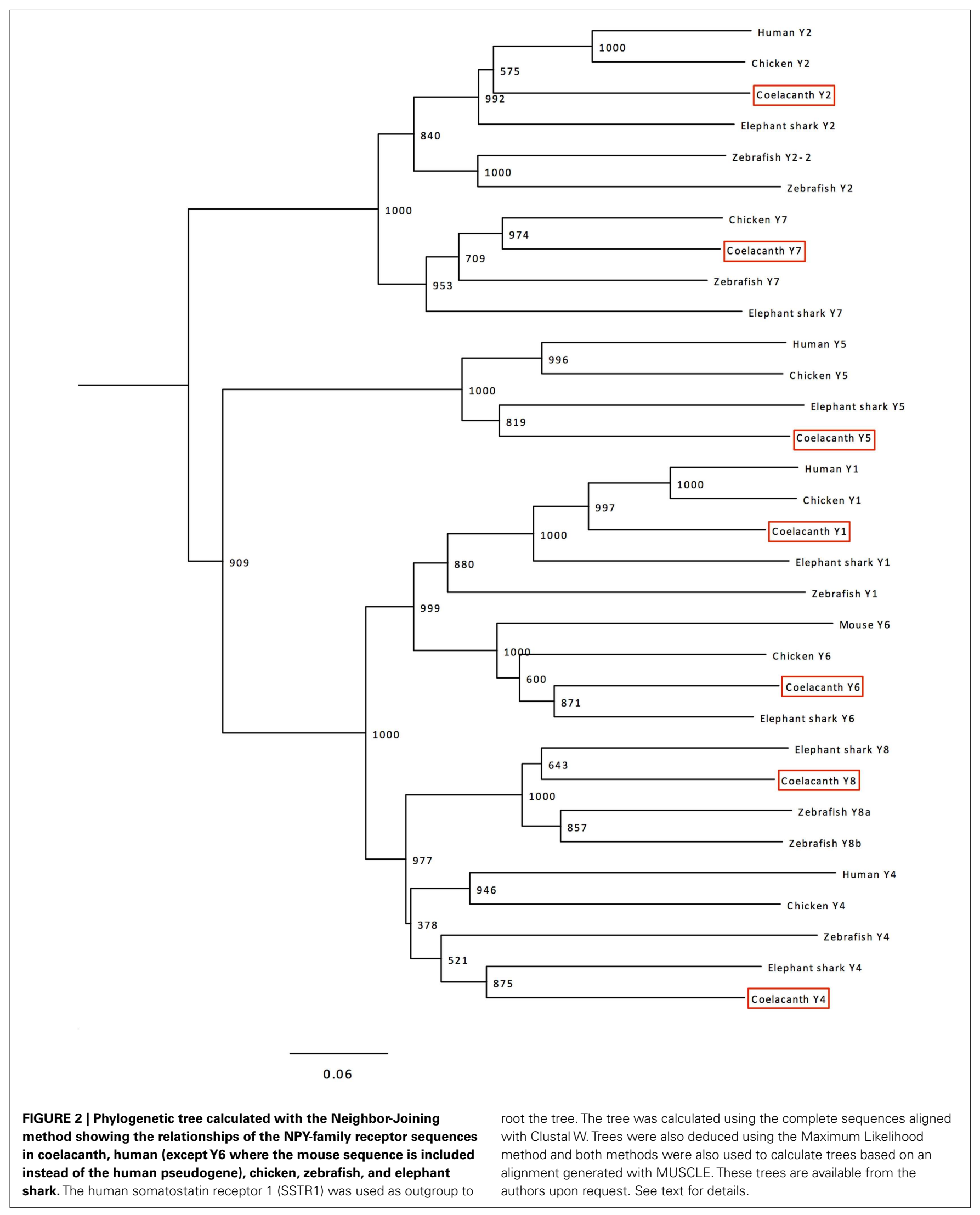




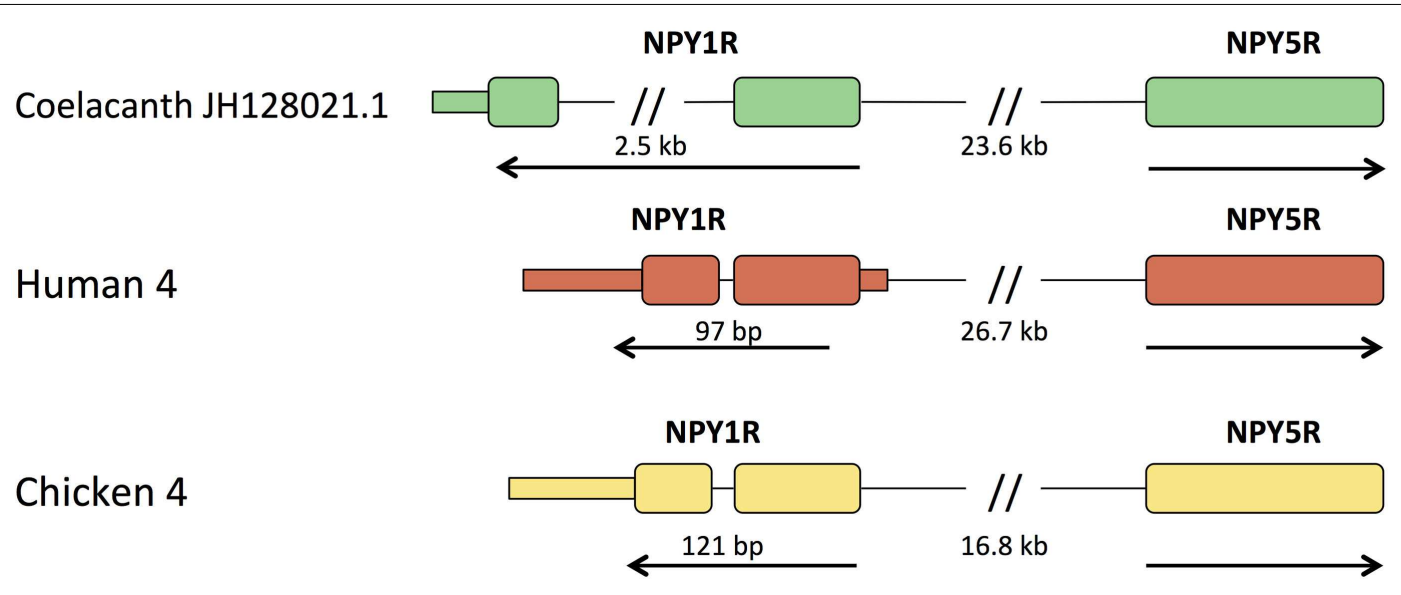

FIGURE 3 | Organization of the $Y 1$ and $Y 5$ genes relative to one another in coelacanth, human, and chicken. Exons are shown as tall boxes for the coding region and low boxes for the 5'- and 3'-untranslated regions where known. The $3^{\prime}$-untranslated region is shown until the position of the first consensus poly(A) signal. The size of the intron in the coding region of $\mathrm{Y} 1$ is shown. In all three species, the genes have a "head-to-head" orientation and may share regulatory upstream elements. The distance between the coding regions of the two genes are shown, but it has not yet been fully explored where promoters and any separate 5 '-untranslated exons may be located.

\section{RESULTS}

\section{LATIMERIA CHALUMNAE NPY-FAMILY RECEPTORS}

We have previously reported the coelacanth Y5 and Y6 genes (Larsson et al., 2007). To identify additional NPY-family receptors, we searched the PreEnsemble Lch database with sequences from other species as queries. The identified Lch sequences were aligned with known NPY-family receptors from other vertebrates and subjected to phylogenetic analyses. Some of the sequences had to be manually curated as indicated in Table 1 which lists all the identified Lch sequences and their Ensemble ID or NCBI accession numbers. The table also lists the sequences for the other species that are included in the alignment and the phylogenetic tree described below. The searches allowed us to identify all the NPY-family receptors known to have arisen before the divergence of the jawed vertebrates, i.e., also Y1, Y2, Y4, Y7, and Y8.

An alignment of all Lch and human NPY-family receptors is shown in Figure 1. All of the sequences contain one to three consensus sequences for $N$-linked glycosylation in the aminoterminal region of the receptors, before transmembrane region 1 (TM1), i.e., the sequence NXS/T. The Lch Y6 and Y8 sequences also have a consensus glycosylation sequence in extracellular loop 2 (EL2), as do human Y1 and Y4. All sequences have a cysteine residue in EL1 and one cysteine in EL2 that presumably form a disulfide bond. The four Y1-subfamily sequences Y1, Y4, Y6, and Y8 also have a cysteine in the aminoterminal region and one in EL3, expected to form an additional disulfide bond, as in Y1-subfamily sequences from other species. Finally, one ore more cysteines are present in the cytoplasmic tail after TM7, expected to serve as attachment sites for palmitate to anchor the tail to the inner side of the cytoplasmic membrane. Also many other positions that are known to be highly conserved among NPY-family receptors, either between species or between receptor subtypes (or both), are conserved in the Lch sequences.

Phylogenetic analyses were performed with a more extensive alignment that included also the sequences of the six chicken
Table 2 |The table lists Ensemble gene ID for the coelacanth and human NPY-family peptides NPY, PYY, and PP (pancreatic polypeptide).

\begin{tabular}{|c|c|c|c|}
\hline Species & Peptide & Ensembl gene ID & $\begin{array}{l}\text { Genome Comment } \\
\text { assembly }\end{array}$ \\
\hline Coelacanth & NPY & ENSLACG00000001891 & LatCha1 \\
\hline Human & NPY & ENSG00000131096 & GRCh37 \\
\hline Coelacanth & PYY & ENSLACG00000015096 & LatCha1 \\
\hline Human & PYY & ENSG00000131096 & GRCh37 \\
\hline Coelacanth & $\begin{array}{l}\text { Pancreatic } \\
\text { polypeptide }\end{array}$ & $\begin{array}{l}\text { Not annotated in } \\
\text { database } \\
(\mathrm{JH} 126680.1: 1,154,715- \\
1,154,819)\end{array}$ & \\
\hline Human & $\begin{array}{l}\text { Pancreatic } \\
\text { polypeptide }\end{array}$ & ENSG00000108849 & GRCh37 \\
\hline
\end{tabular}

The coelacanth entries are shown in bold.

receptors and the seven elephant shark receptors, plus the mouse Y6 sequence as the human Y6 gene is a pseudogene. The resulting tree is shown in Figure 2. The seven Lch sequences could be clearly identified as orthologs to each of the seven previously described receptors in jawed vertebrates. The tree has a few minor deviations from the established order of divergence for the included species, mostly because of higher evolutionary rates for some lineages as explained in the discussion.

In all other vertebrates with assembled genomes, the genes for Y1 and Y5 are located close together in a head-to-head orientation, implying that their promoter regions may share some regulatory elements. The distance between the start codons for the human genes is $26.7 \mathrm{~kb}$ and for the chicken genes $16.8 \mathrm{~kb}$. In the coelacanth, the distance is $23.6 \mathrm{~kb}$ (Figure 3). The promoter regions have not been characterized in detail for Y1 and Y5 in any species and furthermore seem to vary between species with 


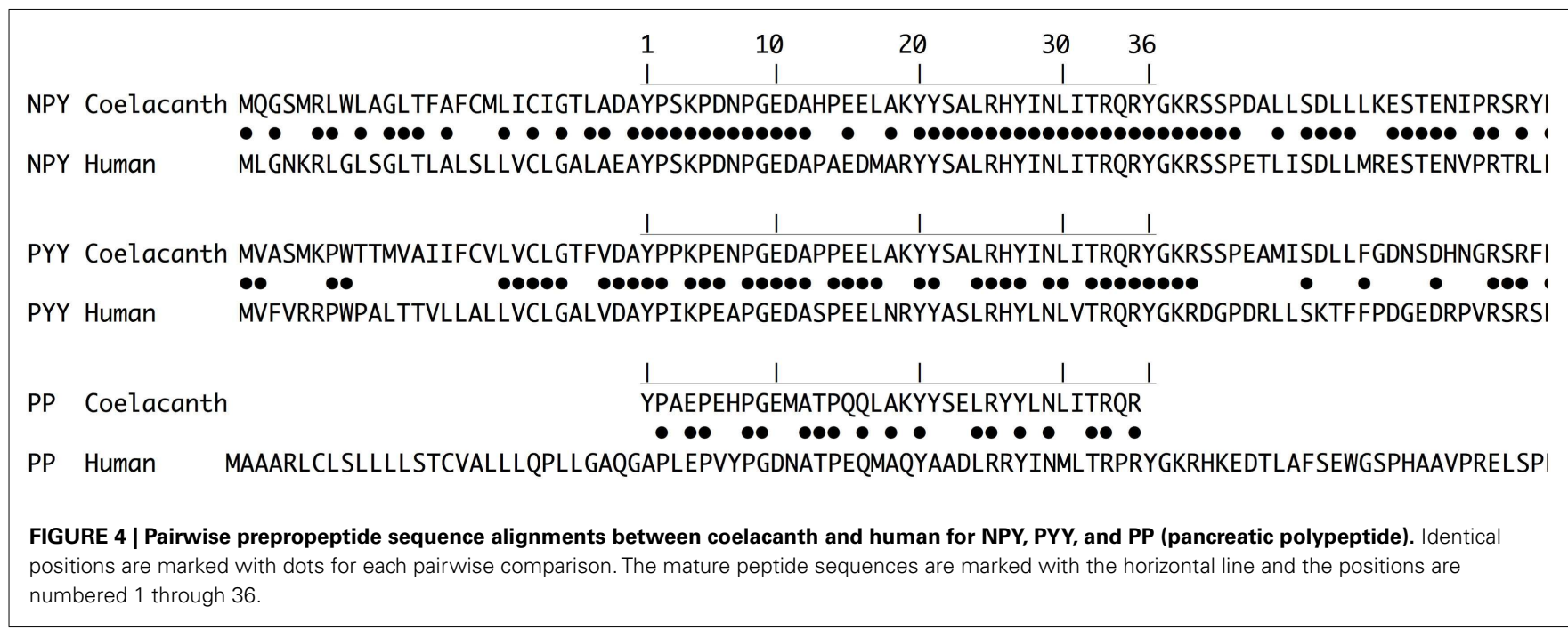

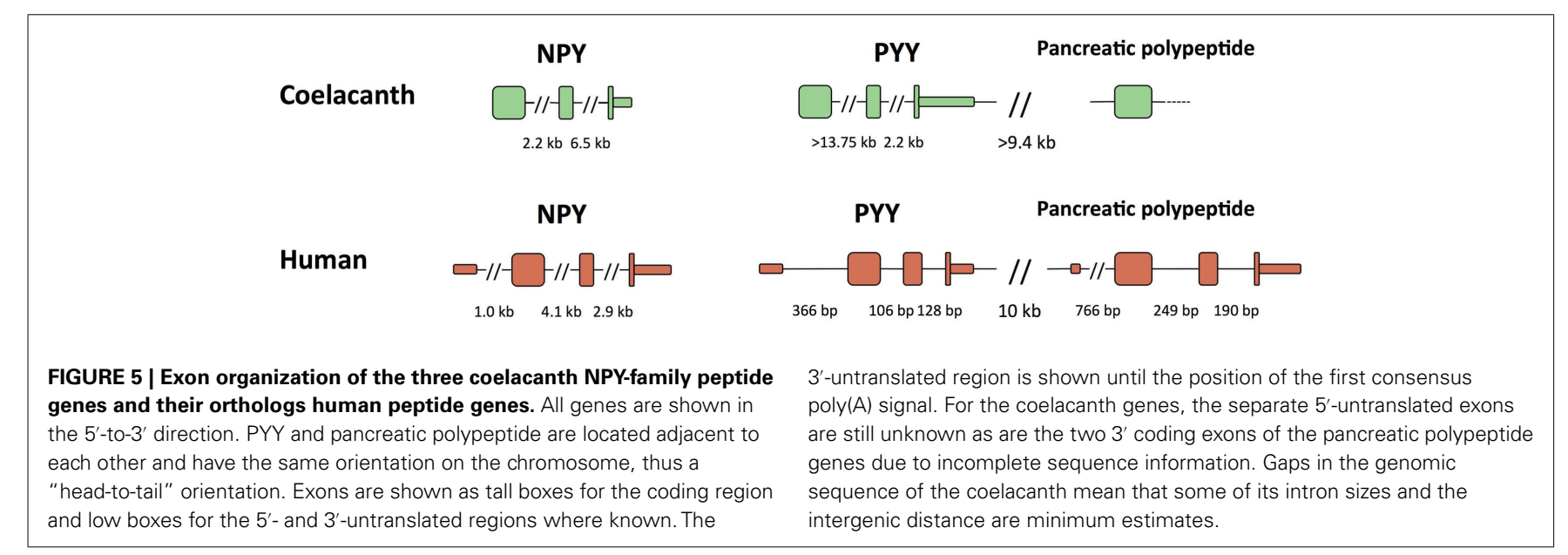

regard to the possibility of multiple promoters and alternatively spliced 5'UTR exons (Wraith, 1999), why a detailed comparison with Lch is not meaningful at this point. The Y1 gene is the only member of the NPY receptor family that has an intron in the coding region. This intron is very small in mammals ( $97 \mathrm{bp}$ in the human gene, $110 \mathrm{bp}$ in opossum), chicken (121 bp), anole lizard (698 bp), and the frog Silurana tropicalis (92 bp; Sundstrom et al., 2012), but considerably larger in zebrafish with approximately $40 \mathrm{~kb}$ (in preparation), a sturgeon (Salaneck et al., 2008), and the two cartilaginous fishes spiny dogfish (Salaneck et al., 2003) and elephant shark (Larsson et al., 2009), the last-mentioned having an intron $>3 \mathrm{~kb}$. In the coelacanth, this intron is approximately $2.5 \mathrm{~kb}$ (Figure 3). Thus, the intron is large both in cartilaginous fishes, a teleost, and the coelacanth. The most parsimonious interpretation is that large size is ancestral and that the intron contracted in the ancestor of tetrapods and has remained small in this lineage.

The synteny groups of the NPY-family receptor genes and their neighboring genes in the same chromosome regions could not be analyzed in the coelacanth due to the small size of the scaffolds as a result of low-coverage sequencing.

\section{LATIMERIA CHALUMNAE NPY-FAMILY PEPTIDES}

The coelacanth genome database was searched with the three human members of the NPY peptide family as queries. Hits were found for the most highly conserved parts of both NPY, PYY, and somewhat surprisingly also PP, although this peptide has not previously been identified outside of the tetrapods. Further analyses revealed the presence of the two small $3^{\prime}$ exons encoding the carboxyterminal extensions of the prepropeptides for NPY and PYY. However, for the more rapidly evolving PP, these exons could not be found, most probably because they are missing in the Lch assembly. The Ensemble gene IDs are listed in Table 2.

An alignment of the coelacanth and human prepropeptides is shown in Figure 4. The mature NPY sequences share 31 och the 36 positions and three of the remaining five are highly conservative replacements, as has been observed for NPY for other vertebrates (Larhammar, 1996; Cerdá-Reverter and Larhammar, 2000). The mature Lch and human PYY sequences share 27 of the 36 positions. The coelacanth PYY sequence is identical to the deduced ancestral vertebrate PYY sequence (not shown), thus the differences are due to divergence of PYY in the lineage leading to humans and other mammals. In contrast, PP has diverged 
considerably between coelacanth and human and the two species share only 18 of the 36 residues, a degree of identity found also for comparisons between birds or frogs and mammals (Larhammar, 1996; Cerdá-Reverter and Larhammar, 2000; Conlon, 2002). For both NPY and PYY, the differences that exist between coelacanth and human are predominantly located in the middle part of the peptides, suggesting that both ends are kept conserved for functional reasons, presumably interactions with the NPY-family receptors.

The genes for Lch NPY and PYY have the coding region distributed over three exons like in all other vertebrates (Figure 5). The introns in the coelacanth PYY gene are much larger, $>13.75$ and $2.2 \mathrm{~kb}$, respectively, than in the mammalian orthologs, with only 106 and $128 \mathrm{bp}$ in human. The introns in chicken and zebrafish are of intermediate size with 2.2 and $0.3 \mathrm{~kb}$ in chicken and similar sizes in zebrafish (Söderberg et al., 2000). For the PP gene, only the exon containing most of the mature PP sequence, preceded by the signal peptide, could be identified. In chicken and mammals, the PYY and PP genes are located in tandem approximately $10 \mathrm{~kb}$ apart. The intergenic distance is of a similar magnitude or greater in the coelacanth (the genomic sequence has a gap in the assembly). All three peptide genes have a separate exon for $5^{\prime} \mathrm{UTR}$ in mammals and this exon has not been identified in any of the coelacanth genes.

\section{DISCUSSION}

The seven NPY-family receptor genes identified in the coelacanth genome database display orthology to the subtypes previously deduced to have arisen in the ancestor of the jawed vertebrates, namely subtypes Y1, Y2, Y4, Y5, Y6, Y7, and Y8 (Figure 3). Thus, the coelacanth has retained the complete ancestral repertoire like the elephant shark, but in contrast to mammals, chicken, and teleost fishes, all of which has lost one or more of the ancestral receptors. Our findings in the coelacanth corroborate our previous gene duplication scenario for the family of NPY receptors (Figure 6), with an ancestral local gene triplication, defining the three subfamilies of Y1, Y2, and Y5, followed by the chromosome quadruplication resulting from the two basal vertebrate tetraploidizations (Larhammar and Salaneck, 2004). Recent studies of other receptor families for neuroendocrine peptide-receptors have also revealed surprising ancestral vertebrate complexity, with six ancient somatostatin receptors (Ocampo Daza et al., 2012), six ancestral oxytocin-vasopressin receptors (Ocampo Daza et al., 2011; Yamaguchi et al., 2012; Ocampo Daza, 2013), and four ancestral GnRH (gonadotropin-releasing hormone) receptors (Kim et al., 2011), followed by losses of genes in mammals as well as other vertebrate lineages.

The clades in the NJ tree shown in Figure 2 corresponding to the seven receptor subtypes have high bootstrap support, except for the Y4-Y8 clade which often has been found to display poor resolution (Larsson et al., 2008, 2009) due to faster evolution of the Y4 sequences (Lundell et al., 2002) and the deviating amino acid composition of the zebrafish Y4 receptor, initially named Ya (Starbäck et al., 1999; see Salaneck et al., 2003). Analyses with the ML method give similar topology with this repertoire of species (not shown). Also when additional species are included for NJ and ML, these receptor subtypes fail to form completely separate

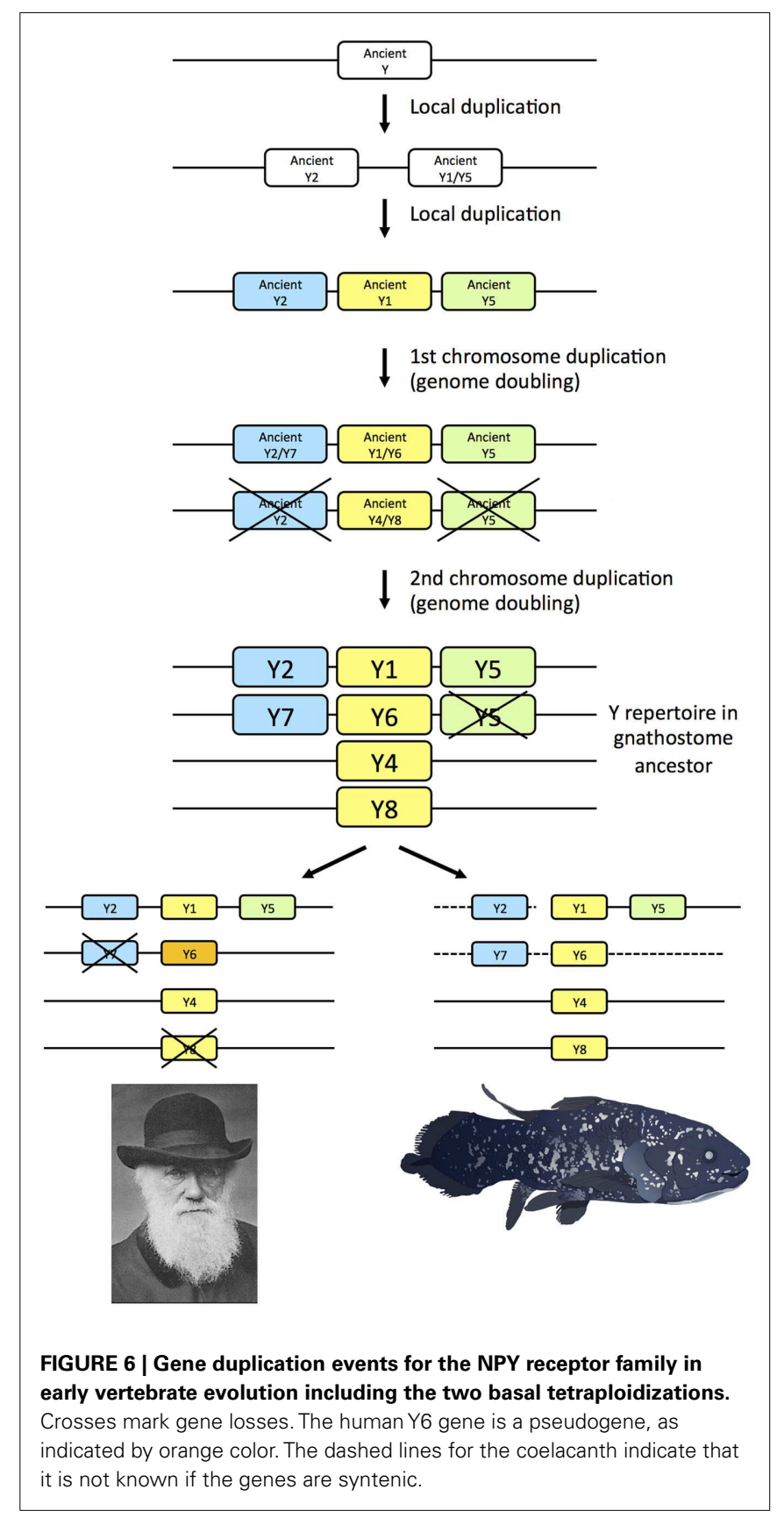

clades with high bootstrap values, but the orthology relationships between tetrapods and teleosts have been confirmed by conserved synteny for Y4 and Y8 (Larsson et al., 2008). The seven coelacanth receptors can clearly be identified as orthologs of the previously identified seven ancestral vertebrate receptors, as shown by the tree in Figure 2.

Within each clade in Figure 2, some deviations from the established evolutionary relationships between species can be seen except Y7 which does indeed conform to the conventional species topology. As has been observed for several other gene or protein families, the zebrafish branch is more basal than the elephant shark, namely for Y1 and Y2. This is probably due to a higher 
evolutionary rate in the teleost fish lineage as compared to cartilaginous fishes and sarcopterygians, as has been observed for conserved non-coding elements (Lee et al., 2011). Also the mouse Y6 branching can probably be accounted for by its higher evolutionary rate. Analyses using the ML method displays similar minor deviations from the species relationships (not shown).

The coelacanth genome project has insufficient coverage for assembly into large scaffolds and therefore does not allow analyses of conserved synteny. Nevertheless, the Y1 and Y5 genes were found to be located close together in a head-to-head orientation like in mammals and chicken, with a similar distance as in human, supporting coregulation of the genes. Y1 and Y5 are known to be coexpressed in brain regions of rat (Parker and Herzog, 1998, 1999; Wolak et al., 2003) and mouse (Naveilhan et al., 1998; Oberto et al., 2007). In the paraventricular region of the hypothalamus, both $\mathrm{Y} 1$ and Y5 are known to contribute to the appetite-stimulating effect of NPY as reviewed in Mercer et al. (2011), probably in slightly different ways (Lecklin et al., 2002, 2003). However, the most important promoters and regulatory elements remain to be functionally identified. Indeed, comparison of the pig promoter regions (Wraith, 1999) with those in human (Herzog et al., 1997) suggested that multiple alternative start sites and/or 5'UTR exons exist that may differ even between these mammals, indicating complicated regulation of the two genes.

Based upon previous studies of the highly conserved peptides NPY and PYY, the identification of these in the coelacanth was expected and both of the mature peptides were found to be highly conserved. Indeed, the coelacanth PYY sequence appears to be identical to that of the deduced vertebrate ancestral PYY sequence (Larhammar, 1996), whereas mammalian PYY has undergone a few amino acid replacements. Possibly, the strong conservation of PYY in the coelacanth indicates a broader expression, like in teleost fishes and lamprey where PYY is expressed in both endocrine cells and neurons (Söderberg et al., 1994, 2000; Cerdá-Reverter et al., 2000; Kurokawa and Suzuki, 2002; Montpetit et al., 2005; Murashita et al., 2006, 2009; Wall and Volkoff, 2013), whereas mammalian PYY is almost exclusively expressed in endocrine cells. Broad distribution and/or usage has been found to correlate with higher conservation (Jordan et al., 2005; Khaitovich et al., 2005).

Our finding of PP in the coelacanth genome was unexpected because this peptide has previously only been identified in tetrapods (Larhammar, 1996; Cerdá-Reverter and Larhammar, 2000; Conlon, 2002; Sundstrom et al., 2008). The discovery of PP in the coelacanth could push back its origin by approximately $50 \mathrm{Myr}$, from a minimum of $340 \mathrm{Myr}$ to a minimum of $390 \mathrm{Myr}$ (Blair and Hedges, 2005). This may even raise the possibility that $\mathrm{PP}$ arose before the divergence of lobefinned fishes and rayfinned fishes, and that the PP gene has been lost in the rayfinned fish lineage. The NPY-family peptides so far described in teleosts have been assigned as NPYa, NPYb, PYYa, and PYYb (previously called

\section{REFERENCES}

Amores, A., Catchen, J., Ferrara, A., Fontenot, Q., and Postlethwait, J. H. (2011). Genome evolution and meiotic maps by massively parallel DNA sequencing: spotted gar, an outgroup for the teleost genome duplication. Genetics 188, 799-808.

Berglund, M. M., Lundell, I., Eriksson, H., Söll, R., Beck-Sickinger, A. G., and Larhammar, D. (2001). Structure-activity analyses of the

PY), with the a and b duplicates having resulted from the teleost tetraploidization 3R (Sundstrom et al., 2008). PP in mammals binds to Y4 with higher affinity than either NPY or PYY, showing that partner preference has evolved between PP and Y4 in this lineage (Lundell et al., 1995, 1996; Berglund et al., 2001). In chicken, in contrast, all three peptides bind to Y4 with similar affinities (Lundell et al., 2002). Interestingly, Lch PP does not have the change from the ancestral residue Gln-34 to Pro-34 that is found in all PP sequences, except a few bird sequences that have a histidine at this position and the caecilian Typhlonectes natans (an amphibian) which has a serine (Conlon et al., 1998; Conlon, 2002). The coelacanth has retained the ancestral Gln-34 found also in all NPY and PYY sequences. This may indicate that Lch PP has a binding profile that differs from PP in tetrapods with regard to receptor subtype preferences.

Detailed studies of peptide-receptor interactions will require cloning and functional expression of the coelacanth receptors and synthesis of the peptides, especially Lch PP. Hopefully future crystallization of NPY-family receptors will provide good templates for structural modeling of the coelacanth receptors and thereby help explain how this peptide-receptor system has evolved in the vertebrates. Unfortunately, studies of the tissue distribution of the mRNA for the NPY-family peptides and receptors cannot be easily performed with this endangered species.

The large repertoire of NPY-family receptors in the coelacanth may either mean that it has retained the ancestral functions for the seven vertebrate receptors or evolved novel functions for some of them. If ancestral functions are maintained, this might give clues to what functions may have disappeared in mammals with the loss of receptors Y7 and Y8, as well as Y6 in several mammalian lineages. Another possibility is that any such functions are partially or completely mediated by the four to five receptors that still exist in mammals. Information on such scenarios may be obtained from studies of species that represent additional basally diverging lineages, such as lungfishes (which unfortunately have very large genomes, thereby complicating bioinformatic analyses) and basal actinopterygians like the spotted gar whose genome was recently assembled (Amores et al., 2011). This species is especially interesting as it diverged before the third tetraploidization took place in the teleost lineage. Also basal lineages among the teleosts have recently added valuable information on gene family evolution, especially the recently assembled genome for the European eel (Henkel et al., 2012). Clearly considerable genetic complexity arose at an early stage in vertebrate evolution that can be deduced by comparing distantly related vertebrate lineages. An inevitable conclusion is that for several gene families, mammals must be considered to have degenerated by gene loss.

\section{ACKNOWLEDGMENTS}

This work was supported by a grant from the Swedish Research Council.

neuropeptide Y-family receptor Y4; studies of the human, rat, and the guinea pig receptors using NPY analogues and two distinct radioligands. Peptides 22, 351-356.
Blair, J. E., and Hedges, S. B. (2005). Molecular phylogeny and divergence times of deuterostome animals. Mol. Biol. Evol. 22, 2275-2284.

Brumovsky, P., Shi, T. S., Landry, M., Villar, M. J., and Hokfelt, T. (2007). 
Brumovsky, Neuropeptide tyrosine and pain. Trends Pharmacol. Sci. 28, 93-102.

Cerdá-Reverter, J. M., and Larhammar, D. (2000). Neuropeptide Y family of peptides: structure, anatomical expression, function, and molecular evolution. Biochem. Cell Biol. 78, 371-392.

Cerdá-Reverter, J. M., MartínezRodriguez, G., Anglade, I., Kah, O., and Zanuy, S. (2000). Peptide YY (PYY) and fish pancreatic peptide Y (PY) expression in the brain of the sea bass (Dicentrarchus labrax) as revealed by in situ hybridization. $J$. Comp. Neurol. 426, 197-208.

Chen, M., Zou, M., Yang, L., and He, S. (2012). Basal jawed vertebrate phylogenomics using transcriptomic data from Solexa sequencing. PLoS ONE 7:e36256. doi:10.1371/journal.pone.0036256

Conlon, J. M. (2002). The origin and evolution of peptide YY (PYY) and pancreatic polypeptide (PP). Peptides 23, 269-278.

Conlon, J. M., Platz, J. E., Chartrel, N., Vaudry, H., and Nielsen, P. F. (1998). Amino acid sequence diversity of pancreatic polypeptide among the amphibia. Gen. Comp. Endocrinol. $112,146-152$.

Dores, R. M., and Baron, A. J. (2011). Evolution of POMC: origin, phylogeny, posttranslational processing, and the melanocortins. Ann. N. Y. Acad. Sci. 1220, 34-48.

Fallmar, H., Sundstrom, G., Lundell, I., Mohell, N., and Larhammar, D. (2011). Neuropeptide Y/peptide YY receptor Y2 duplicate in zebrafish with unique introns displays distinct peptide binding properties. Comp. Biochem. Physiol. B Biochem. Mol. Biol. 160, 166-173.

Guindon, S., Dufayard, J. F., Lefort, V., Anisimova, M., Hordijk, W., and Gascuel, O. (2010). New algorithms and methods to estimate maximumlikelihood phylogenies: assessing the performance of PhyML 3.0. Syst. Biol. 59, 307-321.

Henkel, C. V., Burgerhout, E., de Wijze, D. L., Dirks, R. P., Minegishi, Y., Jansen, H. J., et al. (2012). Primitive duplicate Hox clusters in the European eel's genome. PLoS ONE 7:e32231. doi:10.1371/journal.pone.0032231

Herzog, H., Darby, K., Ball, H., Hort, Y., Beck-Sickinger, A., and Shine, J. (1997). Overlapping gene structure of the human neuropeptide $\mathrm{Y}$ receptor subtypes $\mathrm{Y} 1$ and Y5 suggests coordinate transcriptional regulation. Genomics 41, 315-319.
Herzog, H., Hort, Y. J., Shine, J., and Selbie, L. A. (1993). Molecular cloning, characterization and localization of the human homolog to the reported bovine NPYY 3 receptor: lack of NPY binding and activation. DNA Cell Biol. 12, 465-471.

Hort, Y., Baker, E., Sutherland, G. R., Shine, J., and Herzog, H. (1995). Gene duplication of the human peptide YY gene (PYY) generated the pancreatic polypeptide gene (PPY) on chromosome 17q21.1. Genomics $26,77-83$.

Jaillon, O., Aury, J. M., Brunet, F., Petit, J. L., Stange-Thomann, N., Mauceli, E., et al. (2004). Genome duplication in the teleost fish Tetraodon nigroviridis reveals the early vertebrate proto-karyotype. Nature 431, 946-957.

Jazin, E. E., Yoo, H., Blomqvist, A. G., Yee, F., Weng, G., Walker, M. W., et al. (1993). A proposed bovine neuropeptide Y (NPY) receptor, or its human homologue, confers neither NPY binding sites nor NPY responsiveness on transfected cells. Regul. Pept. 47, 247-258.

Jordan, I. K., Marino-Ramirez, L., and Koonin, E. V. (2005). Evolutionary significance of gene expression divergence. Gene 345, 119-126.

Khaitovich, P., Hellmann, I., Enard, W., Nowick, K., Leinweber, M., Franz, H., et al. (2005). Parallel patterns of evolution in the genomes and transcriptomes of humans and chimpanzees. Science 309, 1850-1854.

Kim, D. K., Cho, E. B., Moon, M. J., Park, S., Hwang, J. I., Kah, O., et al. (2011). Revisiting the evolution of gonadotropin-releasing hormones and their receptors in vertebrates: secrets hidden in genomes. Gen. Comp. Endocrinol. 170, 68-78.

Kurokawa, T., and Suzuki, T. (2002). Development of neuropeptide Yrelated peptides in the digestive organs during the larval stage of Japanese flounder, Paralichthys olivaceus. Gen. Comp. Endocrinol. 126, 30-38.

Larhammar, D. (1996). Evolution of neuropeptide Y, peptide YY, and pancreatic polypeptide. Regul. Pept. 62, 1-11.

Larhammar, D., and Salaneck, E. (2004). Molecular evolution of NPY receptor subtypes. Neuropeptides 38, 141-151.

Larkin, M. A., Blackshields, G., Brown, N. P., Chenna, R., McGettigan, P. A., McWilliam, H., et al. (2007). Clustal W and Clustal X version 2.0. Bioinformatics 23, 2947-2948.

Larsson, T. A., Larson, E. T., and Larhammar, D. (2007). Cloning and sequence analysis of the neuropeptide $\mathrm{Y}$ receptors $\mathrm{Y} 5$ and Y6 in the coelacanth Latimeria chalumnae. Gen. Comp. Endocrinol. $150,337-342$

Larsson, T. A., Olsson, F., Sundstrom, G., Lundin, L. G., Brenner, S., Venkatesh, B., et al. (2008). Early vertebrate chromosome duplications and the evolution of the neuropeptide $\mathrm{Y}$ receptor gene regions. BMC Evol. Biol. 8:184. doi:10.1186/1471-21488-184

Larsson, T. A., Tay, B. H., Sundstrom, G., Fredriksson, R., Brenner, S., Larhammar, D., et al. (2009). Neuropeptide Y-family peptides and receptors in the elephant shark, Callorhinchus milii confirm gene duplications before the gnathostome radiation. Genomics 93, 254-260.

Lecklin, A., Lundell, I., Paananen, L. Wikberg, J. E., Mannistö, P. T., and Larhammar, D. (2002). Receptor subtypes Y1 and Y5 mediate neuropeptide $\mathrm{Y}$ induced feeding in the guinea-pig. Br. J. Pharmacol. 135 2029-2037.

Lecklin, A., Lundell, I., Salmela, S., BeckSickinger, A. G., and Larhammar, D. (2003). Agonists for neuropeptide $Y$ receptors $\mathrm{Y} 1$ and $\mathrm{Y} 5$ stimulate different phases of feeding in guinea pigs. Br. J. Pharmacol. 139, 1433-1440.

Lee, A. P., Kerk, S. Y., Tan, Y. Y., Brenner, S., and Venkatesh, B. (2011). Ancient vertebrate conserved noncoding elements have been evolving rapidly in teleost fishes. Mol. Biol. Evol. 28 1205-1215.

Liang, L., Reinick, C., Angleson, J. K., and Dores, R. M. (2013). Evolution of melanocortin receptors in cartilaginous fish: melanocortin receptors and the stress axis in elasmobranches. Gen. Comp. Endocrinol. 181, 4-9.

Lundell, I., Blomqvist, A. G., Berglund, M. M., Schober, D. A., Johnson, D., Statnick, M. A., et al. (1995). Cloning of a human receptor of the NPY receptor family with high affinity for pancreatic polypeptide and peptide YY. J. Biol. Chem. 270, 29123-29128.

Lundell, I., Boswell, T., and Larhammar, D. (2002). Chicken neuropeptide Y-family receptor Y4: a receptor with equal affinity for pancreatic polypeptide, neuropeptide $\mathrm{Y}$ and peptide YY. J. Mol. Endocrinol. 28, 225-235.

Lundell, I., Statnick, M. A., Johnson, D., Schober, D. A., Starbäck, P., Gehlert, D. R., et al. (1996). The cloned rat pancreatic polypeptide receptor exhibits profound differences to the orthologous human receptor. Proc. Natl. Acad. Sci. U.S.A. 93, 5111-5115.

Matsumoto, M., Nomura, T., Momoses, K., Ikeda, Y., Kondou, Y., Akiho, H., et al. (1996). Inactivation of a novel neuropeptide Y/peptide YY receptor gene in primate species. J. Biol. Chem. 271, 27217-27220.

Mercer, R. E., Chee, M. J., and Colmers, W. F. (2011). The role of NPY in hypothalamic mediated food intake. Front. Neuroendocrinol. 32, 398-415.

Montpetit, C. J., Chatalov, V., Yuk, J., Rasaratnam, I., and Youson, J. H. (2005). "Expression of neuropeptide $\mathrm{Y}$ family peptides in the brain and gut during stages of the life cycle of a parasitic lamprey (Petromyzon marinus) and a nonparasitic lamprey (Ichthyomyzon gagei)," in Trends in Comparative Endocrinology and Neurobiology, eds H. Vaudry, E. Roubos, L. Schoofs, G. Flik, and D. Larhammar (New York: The New York Academy of Sciences), 140-149. Murashita, K., Fukada, H., Hosokawa, H., and Masumoto, T. (2006). Cholecystokinin and peptide $\mathrm{Y}$ in yellowtail (Seriola quinqueradiata): molecular cloning, real-time quantitative RT-PCR, and response to feeding and fasting. Gen. Comp. Endocrinol. 145, 287-297.

Murashita, K., Kurokawa, T., Nilsen, T. O., and Ronnestad, I. (2009). Ghrelin, cholecystokinin, and peptide YY in Atlantic salmon (Salmo salar): molecular cloning and tissue expression. Gen. Comp. Endocrinol. 160, 223-235.

Nakatani, Y., Takeda, H., Kohara, Y., and Morishita, S. (2007). Reconstruction of the vertebrate ancestral genome reveals dynamic genome reorganization in early vertebrates. Genome Res. 17, 1254-1265.

Naveilhan, P., Neveu, I., Arenas, E., and Ernfors, P. (1998). Complementary and overlapping expression of $\mathrm{Y} 1$ $\mathrm{Y} 2$, and $\mathrm{Y} 5$ receptors in the developing and adult mouse nervous system. Neuroscience 87, 289-302.

Oberto, A., Acquadro, E., Bus, T., Sprengel, R., and Eva, C. (2007). Expression patterns of promoters for NPY Y(1) and Y(5) receptors in Y(5)RitTA and Y(1)RVenus BACtransgenic mice. Eur. J. Neurosci. 26, 155-170.

Ocampo Daza, D. (2013). Evolution of Vertebrate Endocrine and Neuronal Gene Families: Focus on Pituitary and Retina. Digital Comprehensive Summaries of Uppsala Dissertations from the Faculty of Medicine. Available at: http://uu.diva-portal. org $/ \mathrm{smash} /$ record .jsf; jsessionid $=$ 
a7e31d1a81174723ce69892e197e? pid=diva2:587276

Ocampo Daza, D., Lewicka, M., and Larhammar, D. (2011). The oxytocin/vasopressin receptor family has at least five members in the gnathostome lineage, inclucing two distinct V2 subtypes. Gen. Comp. Endocrinol. 175, 135-143.

Ocampo Daza, D., Sundstrom, G., Bergqvist, C. A., and Larhammar, D. (2012). The evolution of vertebrate somatostatin receptors and their gene regions involves extensive chromosomal rearrangements. BMC Evol. Biol. 12:231. doi:10.1186/1471-2148-12-231

Parker, R. M., and Herzog, H. (1998). Comparison of Y-receptor subtype expression in the rat hippocampus. Regul. Pept. 75-76, 109-115.

Parker, R. M., and Herzog, H. (1999). Regional distribution of Y-receptor subtype mRNAs in rat brain. Eur. J. Neurosci. 11, 1431-1448.

Pedrazzini, T., Pralong, F., and Grouzmann, E. (2003). Neuropeptide Y: the universal soldier. Cell. Mol. Life Sci. 60, 350-377.

Putnam, N. H., Butts, T., Ferrier, D. E., Furlong, R. F., Hellsten, U., Kawashima, T., et al. (2008). The amphioxus genome and the evolution of the chordate karyotype. Nature 453, 1064-1071.

Saitou, N., and Nei, M. (1987). The neighbor joining method: a new method for reconstructing phylogenetic trees. Mol. Biol. Evol. 4, 406-425.

Salaneck, E., Ardell, D., Larson, E. T., and Larhammar, D. (2003). Three neuropeptide Y receptors in the spiny dogfish, Squalus acanthias, support chromosome doublings in early vertebrate evolution. Mol. Biol. Evol. 20, 1271-1280.

Salaneck, E., Fredriksson, R., Larson, E. T., Conlon, J. M., and Larhammar, D. (2001). A neuropeptide Y receptor Y1-subfamily gene from an agnathan, the European river lamprey. A potential ancestral gene. Eur. J. Biochem. 268, 6146-6154.

Salaneck, E., Larsson, T. A., Larson, E. T., and Larhammar, D. (2008). Birth and death of neuropeptide Y receptor genes in relation to the teleost fish tetraploidization. Gene 409, 61-71.

Shan, Y., and Gras, R. (2011). 43 genes support the lungfish-coelacanth grouping related to the closest living relative of tetrapods with the Bayesian method under the coalescence model. BMC Res. Notes 4:49. doi:10.1186/1756-0500-4-49

Söderberg, C., Pieribone, V. A., Dahlstrand, J., Brodin, L., and Larhammar, D. (1994). Neuropeptide role of both peptide YY and neuropeptide $\mathrm{Y}$ in vertebrates suggested by abundant expression of their mRNAs in a cyclostome brain. J. Neurosci. Res. 37, 633-640.

Söderberg, C., Wraith, A., Ringvall, M., Yan, Y.-L., Postlethwait, J., Brodin, L., et al. (2000). Zebrafish genes for neuropeptide $\mathrm{Y}$ and peptide YY reveal origin by chromosome duplication from an ancestral gene linked to the homeobox cluster. J. Neurochem. 75, 908-918.

Starbäck, P., Lundell, I., Fredriksson, R., Berglund, M. M., Yan, Y.-L., Wraith, A., et al. (1999). Neuropeptide Y receptor subtype with unique properties cloned in the zebrafish; the zYa receptor. Brain Res. Mol. Brain Res. 70, 242-252.

Starbäck, P., Wraith, A., Eriksson, H., and Larhammar, D. (2000). Neuropeptide Y receptor gene y6: multiple deaths or resurrection? Biochem. Biophys. Res. Commun. 277, 264-269.

Sundstrom, G., Dreborg, S., and Larhammar, D. (2010). Concomitant duplications of opioid peptide and receptor genes before the origin of jawed vertebrates. PLoS ONE 5:e10512. doi:10.1371/journal.pone.0010512

Sundstrom, G., Larsson, T. A., Brenner, S., Venkatesh, B., and Larhammar,
D. (2008). Evolution of the neuropeptide $\mathrm{Y}$ family: new genes by chromosome duplications in early vertebrates and in teleost fishes. Gen. Comp. Endocrinol. 155 705-716.

Sundstrom, G., Xu, B., Larsson, T. A. Heldin, J., Bergqvist, C. A., Fredriksson, R., et al. (2012). Characterization of the neuropeptide $\mathrm{Y}$ system in the frog Silurana tropicalis (Pipidae): three peptides and six receptor subtypes. Gen. Comp. Endocrinol. 177, 322-331.

Tostivint, H., Lihrmann, I., and Vaudry, H. (2008). New insight into the molecular evolution of the somatostatin family. Mol. Cell. Endocrinol. 286, 5-17.

Wall, A., and Volkoff, H. (2013). Effects of fasting and feeding on the brain mRNA expressions of orexin, tyrosine hydroxylase (TH), PYY and CCK in the Mexican blind cavefish (Astyanax fasciatus mexicanus). Gen. Comp. Endocrinol. 183, 44-52.

Waterhouse, A. M., Procter, J. B., Martin, D. M., Clamp, M., and Barton, G. J. (2009). Jalview version 2: a multiple sequence alignment editor and analysis workbench. Bioinformatics 25, 1189-1191.

Wolak, M. L., Dejoseph, M. R., Cator, A. D., Mokashi, A. S., Brownfield, M. S. and Urban, J. H. (2003). Comparative distribution of neuropeptide $\mathrm{Y}$ $\mathrm{Y} 1$ and $\mathrm{Y} 5$ receptors in the rat brain by using immunohistochemistry. $J$. Comp. Neurol. 464, 285-311.

Wraith, A. (1999). Molecular Evolution of the Neuropeptide Y Receptor Family. Insights from Mammals and Fish. Uppsala: Uppsala University. [Comprehensive Summaries of Uppsala Dissertations from the Faculty of Medicine 893, ISBN 91-554-46116].

Wraith, A., Törnsten, A., Chardon, P., Harbitz, I., Chowdhary, B. P., Andersson, L., et al. (2000). Evolution of the neuropeptide $\mathrm{Y}$ receptor family: gene and chromosome duplications deduced from the cloning of the five receptor subtype genes in pig. Genome Res. 10, 302-310.

$\mathrm{Xu}, \mathrm{B}$., Sundstrom, G., Kuraku, S., Lundell, I., and Larhammar, D. (2012). Cloning and pharmacological characterization of the neuropeptide $\mathrm{Y}$ receptor Y5 in the sea lamprey, Petromyzon marinus. Peptides 39C, 64-70.

Yamaguchi, Y., Kaiya, H., Konno, N., Iwata, E., Miyazato, M., Uchiyama M., et al. (2012). The fifth neurohypophysial hormone receptor is structurally related to the V2-type receptor but functionally similar to V1-type receptors. Gen. Comp. Endocrinol. 178, 519-528.

Zhang, L., Bijker, M. S., and Herzog, H. (2011). The neuropeptide Y system: pathophysiological and therapeutic implications in obesity and cancer. Pharmacol. Ther. 131, 91-113.

Conflict of Interest Statement: The authors declare that the research was conducted in the absence of any commercial or financial relationships that could be construed as a potential conflict of interest.

Received: 15 January 2013; accepted: 15 February 2013; published online: 08 March 2013.

Citation: Larhammar $D$ and Bergqvist $C A$ (2013) Ancient grandeur of the vertebrate neuropeptide $Y$ system shown by the coelacanth Latimeria chalumnae. Front. Neurosci. 7:27. doi: 10.3389/fnins.2013.00027

This article was submitted to Frontiers in Neuroendocrine Science, a specialty of Frontiers in Neuroscience.

Copyright (c) 2013 Larhammar and Bergqvist. This is an open-access article distributed under the terms of the Creative Commons Attribution License, which permits use, distribution and reproduction in other forums, provided the original authors and source are credited and subject to any copyright notices concerning any third-party graphics etc. 